\title{
OSTEOPOROSIS IS ACCOMPANIED BY REDUCED CD274 EXPRESSION IN HUMAN BONE MARROW-DERIVED MESENCHYMAL STEM CELLS
}

\author{
A-N. Zeller ${ }^{1,2, *}$, M. Selle ${ }^{1}$, Z. Gong ${ }^{1}$, M. Winkelmann ${ }^{1}$, C. Krettek ${ }^{1}$, K. Bundkirchen ${ }^{1}$, C. Neunaber ${ }^{1, \S}$ \\ and S. Noack ${ }^{1, \S}$ \\ ${ }^{1}$ Trauma Department, Hannover Medical School, Carl-Neuberg-Str. 1, 30625 Hannover, Germany \\ ${ }^{2}$ Department of Cranio-Maxillo-Facial Surgery, Hannover Medical School, Carl-Neuberg-Str. 1, 30625 \\ Hannover, Germany \\ $\S$ These authors contributed equally to this work
}

\begin{abstract}
Underlying pathomechanisms of osteoporosis are still not fully elucidated. Cell-based therapy approaches pose new possibilities to treat osteoporosis and its complications. The aim of this study was to quantify differences in human bone marrow-derived mesenchymal stem cells (hBMSCs) between healthy donors and those suffering from clinically manifest osteoporosis.

Cell samples of seven donors for each group were selected retrospectively from the hBMSC cell bank of the Trauma Department of Hannover Medical School. Cells were evaluated for their adipogenic, osteogenic and chondrogenic differentiation potential, for their proliferation potential and expression of surface antigens. Furthermore, a RT2 Osteoporosis Profiler PCR array, as well as quantitative real-time PCR were carried out to evaluate changes in gene expression.

Cultivated hBMSCs from osteoporotic donors showed significantly lower cell surface expression of CD274 (4.98 \% $\pm 2.38 \%)$ than those from the control group $(26.03 \% \pm 13.39 \% ; p=0.007)$, as assessed by flow cytometry. In osteoporotic patients, genes involved in inhibition of the anabolic WNT signalling pathway and those associated with stimulation of bone resorption were significantly upregulated. Apart from these changes, no significant differences were found for the other cell surface antigens, adipogenic, osteogenic and chondrogenic differentiation ability as well as proliferation potential.

These findings supported the theory of an influence of CD274 on the regulation of bone metabolism. CD274 might be a promising target for further investigations of the pathogenesis of osteoporosis and of cell-based therapies involving MSCs.
\end{abstract}

Keywords: Osteoporosis, mesenchymal stem cells, CD274, osteoblasts, gene expression.

*Address for correspondence: A-N. Zeller, Trauma Department, Hannover Medical School, Carl-NeubergStr. 1, 30625 Hannover, Germany.

Telephone number: +49 5115322050 Email: zeller.alexander@mh-hannover.de

Copyright policy: This article is distributed in accordance with Creative Commons Attribution Licence (http://creativecommons.org/licenses/by-sa/4.0/).

\begin{tabular}{|c|c|c|c|}
\hline & List of Abbrevations & DMSO & dimethyl sulphoxide \\
\hline & & EDTA & ethylenediaminetetraacetic acid \\
\hline ALOX15 & arachidonate 15-lipoxygenase & FACS & fluorescence-activated cell sorting \\
\hline APC & allophycocyanin & FBS & foetal bovine serum \\
\hline BMP & bone morphogenetic protein & FC & flow cytometry \\
\hline CD & cluster of differentiation & FCS & foetal calf serum \\
\hline CFU-F & colony forming unit-fibroblast & FGF2 & basic fibroblast growth factor \\
\hline CTLA-4 & cytotoxic T-lymphocyte associated & FITC & fluorescein isothiocyanate \\
\hline & protein 4 & GHRH & growth hormone releasing hormone \\
\hline $\mathrm{Ct}$ & cycle threshold & hBMSCs & human bone marrow-derived MSCs \\
\hline Су7 & cyanine dye 7 & HEPES & 2-[4-(2-hydroxyethyl)piperazine-1- \\
\hline DEXA & dual-energy absorptiometry & & yl]ethanesulphonic acid \\
\hline DKK1 & $\begin{array}{l}\text { Dickkopf WNT signalling pathway } \\
\text { inhibitor } 1\end{array}$ & HPRT1 & $\begin{array}{l}\text { hypoxanthine } \\
\text { phosphoribosyltransferase } 1\end{array}$ \\
\hline DMEM & Dulbecco's modified Eagle Medium & IBMX & 3-isobutyl-1-methylxanthine \\
\hline
\end{tabular}




$\begin{array}{ll}\text { IL6 } & \text { interleukin 6 } \\ \text { IL6R } & \text { IL6 receptor } \\ \text { ISCT } & \text { International Society for Cellular } \\ & \text { Therapy } \\ \text { ITS } & \text { insulin, transferrin, sodium selenite } \\ \text { MRI } & \text { magnetic resonance imaging } \\ \text { MRONJ } & \text { medication induced necrosis of the } \\ & \text { jaw } \\ \text { MSCs } & \text { mesenchymal stem cells } \\ \text { NFATC1 } & \text { nuclear factor of activated T cells 1 } \\ \text { P1 } & \text { passage 1 } \\ \text { P3 } & \text { passage 3 } \\ \text { PBS } & \text { phosphate-buffered saline } \\ \text { PD-1/PDCD1 } & \text { programmed cell death-1 } \\ \text { PD-L1 } & \text { PD-1 ligand } \\ \text { PE } & \text { phycoerythrin } \\ \text { PerCP } & \text { peridinin-chlorophyll-protein } \\ \text { PRL } & \text { prolactin } \\ \text { PTH } & \text { parathyroid hormone } \\ \text { PTHLH } & \text { parathyroid-hormone-like hormone } \\ \text { RANKL } & \text { receptor activator of nuclear factor } \\ & \text { kappa-B ligand } \\ \text { SFRP1 } & \text { secreted-frizzled-related protein 1 } \\ \text { SOST } & \text { sclerostin } \\ \text { TGF- } 33 & \text { transforming growth factor beta 3 }\end{array}$

\section{Introduction}

Despite the increased incidence of osteoporosis in the ageing society (Burge et al., 2007; Johnell and Kanis, 2005), its underlying pathomechanisms have not been fully elucidated. Immunological factors (Arron and Choi, 2000; Nagahama et al., 2004) and altered mechanisms of osteogenic cell differentiation have been postulated (Rodríguez et al., 1999).

As MSCs have the ability of constant self-renewal and can differentiate into several cell types in vivo and in vitro, they are of great interest for research in the fields of regenerative medicine and tissue engineering (Docheva et al., 2007; Kassem et al., 2004). MSCs can be found in most tissues of the human body. Besides aspirates from liposuction, they can be harvested safely by minimal invasive aspiration biopsy from bone marrow stroma (Chamberlain et al., 2007). They can be identified in vitro by growing plastic-adherent, their differentiation potential and a set of surface markers (Bara et al., 2014; Dominici et al., 2006; Machado et al., 2013). However, no consensus exists regarding their surface marker expression.

MSCs can differentiate into osteoblasts, adipocytes, chondrocytes and other non-mesoderm-type cells in vitro (Banas et al., 2007; Docheva et al., 2007; Kassem et al., 2004). Therefore, their immense differentiation potential has raised hope for future use in standardised, cell-based therapy approaches (Ayatollahi et al., 2012; Kassem et al., 2004; Wang et al., 2012). As MSCs are able to differentiate into osteoblasts, they have the potential to perform intramembranous bone formation, which makes their therapeutic use applicable especially in reconstructive and regenerative therapies for bone defects (Gibon et al., 2017). Furthermore, MSC do not express T and $\mathrm{B}$ cell markers and may inhibit T cell proliferation through direct contact and cytokine secretion (Zhao et al., 2004). These immune-modulatory and immune evasive properties might facilitate the use of MSCs for cell-based therapies, especially for degenerative conditions. Cell therapies for osteoporosis involving MSCs (Aghebati-Maleki et al., 2019; Antebi et al., 2014) have been discussed, but have so far not been established in clinical use.

A heterogenic set of factors responsible for osteoporosis such as age, medication and genetics (Cummings and Melton, 2002) may be accountable for heterogeneous distribution of clinical manifestations. Donors' age has been described as a factor for reduced osteogenic and chondrogenic potential of MSCs in a murine model (Kretlow et al., 2008). The co-incidence of age-related decrease in osteoblastic differentiation (Zhou et al., 2008) suggests a possible link between BMSC differentiation potential and clinical manifestation of osteoporosis. Yet, osteoporosis itself seems not to be associated with a reduced osteogenic potential of MSCs (Haddouti et al., 2020). On the other hand, MSCs derived from femoral heads of patients suffering from osteoporosis show reduced migration ability upon BMP-2, BMP-7 or FCS stimulation (Haasters et al., 2014) and reduced but qualitatively adequate ossification (Prall et al., 2013). Clinical findings and in vitro studies showed increased bone marrow adiposity and a negative association between bone marrow fat and rate of bone formation in osteoporotic patients (Kassem and Marie, 2011; Paccou et al., 2015; Rosen and Bouxsein, 2006). Therefore, a shift from osteogenesis towards adipogenesis for MSCs from osteoporotic patients has been proposed (Kassem and Marie, 2011; Rosen and Bouxsein, 2006). Furthermore, a link between osteoporosis and decreased proliferation rates of MSCs harvested from iliac crest aspirates has been reported (Rodríguez et al., 1999). Moreover, there is evidence that anti-resorptive substances routinely used in the therapy of osteoporosis may interact beneficially with MSCs for bone formation. In vitro, alendronate has a positive effect on osteoblastic differentiation of MSCs from healthy donors (Duque and Rivas, 2007). For osteoporotic patients, cell therapy may also play a role in the treatment of side effects of anti-resorptive substances. In a rat model, beneficial effects of growth factors and cytokines secreted by MSCs were found for cases of medicationrelated osteonecrosis of the jaw (Ogata et al., 2015).

Čamernik et al. (2020) described differences between MSCs from osteoporotic patients and non-osteoporotic patients. In their work, after chondrogenic differentiation, the pellet diameter of bone-derived MSCs from osteoporotic donors was significantly smaller compared to controls. Also, deficiency in CD152 (CTLA-4) and CD279 (PD-1), 
a receptor of CD274, have been linked to bone malformation in a murine model (Nagahama et al., 2004). Hypermethylation of the CD279 gene locus, PDCD1, has recently been linked to the occurrence of osteoporosis in postmenopausal women (Cheishvili et al., 2018).

As little is known about possible effects of altered MSCs on bone metabolism, the aim of the present study was to investigate differences between hBMSCs from osteoporotic and non-osteoporotic donors. The study especially focused on evaluating differences within their osteogenic, adipogenic and chondrogenic differentiation potential, proliferation ability as well as alternations in surface antigen and gene expression.

\section{Materials and Methods}

Inclusion and exclusion criteria and donors' consent All tissue samples were acquired by bone marrow aspiration from volunteers undergoing elective surgical procedures at the Trauma Department of Hannover Medical School, Hannover, Germany. Donors suffering from clinically relevant osteoporosis were included in the study group. Criteria for inclusion were previous pathological fractures, vertebral wedge fractures and $\mathrm{T}$ scores $\leq-2.5$ in DEXA scan. Immunosuppressed patients and those suffering from malignant diseases were excluded from the study. An anonymous questionnaire about pre-existing conditions and lifestyle as well as reports about secondary diagnoses was obtained from all donors.

Written informed consent was obtained from all donors prior to inclusion in the study. The study protocol and process of sample donation complied with the Declaration of Helsinki and were approved by the institutional review board (Hannover Medical School, Votum number 2562).

\section{MSC purification and proliferation}

After intraoperative bone marrow aspiration from the iliac crest, samples were transferred into PBS (Biochrom) and subsequently separated by centrifugation for $30 \mathrm{~min}$ at $500 \times g$ using a synthetic polysaccharide-epichlorohydrin-copolymer (Biocoll ${ }^{\circledR}$, Biochrom). The centrifuge was allowed to run down without the action of a break in order to prevent the layers from being swirled by the breaking force. Then, the mononuclear cell layer was extracted, washed with PBS and centrifuged for $5 \mathrm{~min}$ at $500 \times g$. Next, the generated pellet was re-suspended in MSC specific growth medium containing DMEM FG 0415 (Biochrom) supplemented with $10 \%$ (v/v) FBS (Hyclone $^{\circledR}$ FBS, Thermo Fisher Scientific), $20 \mathrm{mmol} / \mathrm{L}$ HEPES, $1 \%$ (100 U/mL/100 $\mu \mathrm{g} / \mathrm{mL})$ penicillin/ streptomycin (Biochrom) and $2 \mathrm{ng} / \mathrm{mL}$ human recombinant FGF2 (PeproTech).

To facilitate BMSC proliferation, cells were incubated at $37{ }^{\circ} \mathrm{C}$ and $5 \% \mathrm{CO}_{2}$, as previously described (Schäck et al., 2013). In P1 of in vitro cultivation, cells were cryoconserved using freezing medium containing $95 \%$ FBS and $5 \%$ DMSO. Cells were stored at $-152{ }^{\circ} \mathrm{C}$ in a cell bank for hBMSCs at the Trauma Department of Hannover Medical School for further analyses.

\section{CFU-F assay}

During hBMSC characterisation, a CFU-F assay was carried out at P1 to investigate cells' proliferation potential. Cells were seeded in duplicates in ascending concentrations of 125, 250 and 500 cells per well in a six-well plate. Cells were fixed with methanol (Merck) after $10 \mathrm{~d}$ of incubation at $37^{\circ} \mathrm{C}$ and $5 \% \mathrm{CO}_{2}$. After staining the cells using $1 \%$ crystal violet solution (Merck), macroscopically visible BMSC colonies were counted to calculate the number of colonies per 100 cells seeded.

FC

To assess CD274 expression and to confirm identifying criteria for MSCs, cell samples were analysed by FC. In addition to the criteria defined by Dominici et al. (2006) (expression of CD105, CD73 and CD90 but not of CD45, CD34, CD14 or CD11b, CD79 $\alpha$ or CD19 and HLA-DR), expression of CD29, CD44, CD166, CD11c, CD15 and CD31 was analysed, as postulated in the literature (Bara et al., 2014; Dominici et al., 2006; Machado et al., 2013).

After controlled thawing, cells were incubated, as previously described (Schäck et al., 2013), in MSC specific growth medium. P3 cells were detached using $0.05 \% / 0.02 \%$ trypsin-EDTA solution (Biochrom) and washed twice using FC buffer [2 \% (v/v) FBS in PBS]. All centrifugation steps were performed at $400 \times g$ and $4{ }^{\circ} \mathrm{C}$ for $1 \mathrm{~min}$. For each sample, $1 \times 10^{5}$ cells were used and incubated with appropriate fluorochromeconjugated antibodies for $60 \mathrm{~min}$ at $4{ }^{\circ} \mathrm{C}$ in the dark. The following monoclonal antibodies (mouse antihuman) were used: CD11b APC, CD15 FITC, CD19 PerCP, CD29 APC, CD31 FITC, CD34 PE-Cy7, CD44 FITC, CD45 APC-Cy7, CD73 APC, CD90 PerCP Cy5.5, CD105 PE, CD166 FITC. All antibodies were purchased from BioLegend (San Diego, CA, USA) apart from CD166 FITC, which was purchased from MBL (Woburn, MA, USA). CD274 expression was evaluated during FC analysis using PE anti-human CD274 (B7-H1, PD-L1) antibodies (clone 29E.2A3, Biolegend) (Table 1).

After two washing steps with FC buffer, cells were analysed using a FACS Canto (BD Biosciences) as described before (Schäck et al., 2013). Briefly, for each flow cytometric analysis, $3 \times 10^{4}$ cells were recorded. Cell debris was excluded by using scatter parameters in BD FACSDiva Software and Flowing Software version 2.5.0. Within the analysed surface antigens, minimal standards regarding expression were expected to be met according to those commonly described in the literature (Bara et al., 2014; Dominici et al., 2006; Machado et al., 2013). 
Table 1. Antibodies used for FC Analysis. The following monoclonal antibodies (mouse anti-human) were used for FC analysis.

\begin{tabular}{|c|c|c|c|c|c|}
\hline Antibody & Dye & Volume $(\mu \mathrm{L})$ per $\mathbf{1 0 0} \boldsymbol{\mu L}$ buffer & Clone & Catalugue number & Company \\
\hline CD105 & PE & 1.25 & 43 A3 & 323206 & Biolegend \\
\hline CD11b & APC & 2.50 & ICRF44 & 301310 & Biolegend \\
\hline CD15 & FITC & 0.63 & W6D3 & 323004 & Biolegend \\
\hline CD166 & FITC & 0.40 & 3A6 & K0044-4 & MBL \\
\hline CD19 & PerCP Cy5.5 & 2.50 & HIB19 & 302230 & Biolegend \\
\hline CD274 & PE & 0.63 & 29E.2A3 & 329706 & Biolegend \\
\hline CD29 & APC & 0.03 & TS2/16 & 303018 & Biolegend \\
\hline CD31 & FITC & 1.25 & WM59 & 303104 & Biolegend \\
\hline CD34 & PE-Cy7 & 2.50 & 581 & 343516 & Biolegend \\
\hline CD44 & FITC & 0.20 & BJ18 & 338804 & Biolegend \\
\hline CD45 & APC-Cy7 & 2.00 & H130 & 304014 & Biolegend \\
\hline CD73 & APC & 0.01 & AD2 & 344006 & Biolegend \\
\hline CD90 & PerCP Cy5.5 & 0.50 & $5 E 07$ & 328118 & Biolegend \\
\hline
\end{tabular}

\section{Gene expression}

RT2 Profiler PCR Array Osteoporosis (Gene Globe ID: PAHS-170ZC-2, Qiagen) was carried out as previously described (Bundkirchen et al., 2018). Summarised, RNA was isolated from hBMSCs pellets from three healthy and three osteoporotic donors using the Direct-zol RNA extraction kit (Zymo Research), according to the manufacturer's protocol. RNA quality was determined using an Epoch-Reader (BioTek Instruments). cDNA was synthesised starting from $1 \mu \mathrm{g}$ RNA using the High-Capacity cDNA Reverse Transcriptase Kit (Applied Biosystem) according to the manufacturer's protocol.

For determination of involved signalling pathways, the RT2 Profiler PCR Array Osteoporosis was performed using the Step-OnePlus Real-Time PCR System (Applied Biosystems). For all samples, the threshold was set at $0.075 \Delta R n[\Delta R n=R n$ (post-PCR read) $-\mathrm{Rn}$ (pre-PCR read), where $\mathrm{Rn}=$ normalised reporter]. Ct values were exported to an Excel file. Then, this table was uploaded to a data analysis web portal (Web ref. 1). Samples were assigned to control (healthy donors) and test group (osteoporotic donors). Ct values were normalised based on the reference gene HPRT1. The data analysis web portal calculates fold change/regulation using the $\Delta \Delta \mathrm{Ct}$ method, in which the $\Delta \mathrm{Ct}$ is calculated between a gene of interest and an average of reference genes, followed by $\Delta \Delta \mathrm{Ct}$ calculations [ $\Delta \mathrm{Ct}$ (test group) $-\Delta \mathrm{Ct}$ (control group)]. Then, fold change is calculated using the $2^{-\Delta \Delta C t}$ formula. A fold change of 0.5 or less was considered as a down-regulation, of 2.0 or more as an up-regulation.

Determination of gene expression was performed using TaqMan probes (Applied Biosystems) for the following genes: CD274 (also known as PDL1; Hs00204257_m1), CD279 (also known as PD1; Hs01550088_m1) and CD152 (also known as CTLA4; Hs00175480_m1). As a housekeeping gene, eukaryotic 18S rRNA (Hs9999901 s1) was used. Experiments were carried out with the Step-OnePlus Real-Time PCR System and the corresponding Mastermix (Applied Biosystems). The threshold was set at $0.2 \Delta \mathrm{Rn}$ for all samples. The evaluation of the $\mathrm{Ct}$ values was performed using the $\Delta \Delta \mathrm{Ct}$ method. Statistical analysis was performed with fold change values $\left(2^{-\Delta \Delta C t}\right)$.

\section{Osteogenic differentiation}

To assess the osteogenic potential of each specimen, BMSCs from each donor were transferred onto six-well plates with each well containing a total of 150,000 cells. Samples were incubated either in $3 \mathrm{~mL}$ control medium containing DMEM FG0415 (Biochrom) supplemented with $20 \mathrm{mmol} / \mathrm{L}$ HEPES (Biochrom), $10 \%$ FBS (Thermo Fisher) and $1 \%$ penicillin/streptomycin $(100 \mathrm{U} / \mathrm{mL} / 100 \mu \mathrm{g} / \mathrm{mL}$; Biochrom) or $3 \mathrm{~mL}$ induction medium for osteogenic differentiation supplemented with $10 \mathrm{nmol} / \mathrm{L}$ dexamethsone (Merck), $50 \mu \mathrm{mol} / \mathrm{L}$ ascorbate-2phosphate (Merck) and $3 \mathrm{mmol} / \mathrm{L} \mathrm{Na}_{2} \mathrm{HPO}_{4} / \mathrm{NaH}_{2} \mathrm{PO}_{4}$ at $\mathrm{pH} 7.4$ (Merck) added to the control medium. Medium was changed on a weekly basis. Histological specimens were harvested at days 28 and 42, fixed for $30 \mathrm{~min}$ in $4 \%$ formalin solution and consequently stained using $0.5 \%$ alizarin red S (pH 4.5; Carl Roth).

\section{Adipogenic differentiation}

Apart from a different medium to induce adipogenic differentiation, all specimens underwent the identical procedure as described for osteogenic differentiation. The induction medium for adipogenic differentiation contained $1 \mu \mathrm{mol} / \mathrm{L}$ dexamethasone (Merck), $500 \mu \mathrm{mol} / \mathrm{L}$ IBMX (Merck), $60 \mu \mathrm{mol} / \mathrm{L}$ indomethacin (Merck) and $172 \mathrm{nmol} / \mathrm{L}$ insulin in addition to the aforementioned control medium. Medium was changed on a weekly basis. Histological specimens were harvested at day 28 , fixed in $4 \%$ formalin 
Table 2. Basic parameters within both groups measured by FC analysis. Mean expression and standard deviation in percentage. CD274 expression was significantly decreased in patients with osteoporosis compared to control group $(p=0.007)$. No significant differences were found for all other antigens between the groups.

\begin{tabular}{|c|c|c|}
\hline Antigen & Control group & Osteoporosis group \\
\hline CD11b & $1.17 \% \pm 0.53 \%$ & $1.10 \% \pm 0.33 \%$ \\
\hline CD11c & $4.22 \% \pm 1.92 \%$ & $3.23 \% \pm 1.54 \%$ \\
\hline CD15 & $0.78 \% \pm 0.34 \%$ & $0.87 \% \pm 0.18 \%$ \\
\hline CD19 & $5.19 \% \pm 4.61 \%$ & $2.66 \% \pm 0.65 \%$ \\
\hline CD29 & $89.72 \% \pm 19.44 \%$ & $98.09 \% \pm 1.76 \%$ \\
\hline CD31 & $0.99 \% \pm 0.43 \%$ & $1.23 \% \pm 0.44 \%$ \\
\hline CD34 & $14.65 \% \pm 11.56 \%$ & $14.53 \% \pm 4.78 \%$ \\
\hline CD44 & $81.72 \% \pm 28.83 \%$ & $91.85 \% \pm 5.25 \%$ \\
\hline CD45 & $2.96 \% \pm 1.22 \%$ & $2.46 \% \pm 0.93 \%$ \\
\hline CD73 & $94.14 \% \pm 9.52 \%$ & $94.74 \% \pm 3.31 \%$ \\
\hline CD90 & $95.28 \% \pm 4.54 \%$ & $97.55 \% \pm 0.82 \%$ \\
\hline CD105 & $98.77 \% \pm 1.49 \%$ & $99.35 \% \pm 0.38 \%$ \\
\hline CD166 & $89.30 \% \pm 19.42 \%$ & $97.45 \% \pm 1.21 \%$ \\
\hline CD274 & $26.03 \% \pm 13.39 \%$ & $4.98 \% \pm 2.38 \%$ \\
\hline
\end{tabular}

solution for $30 \mathrm{~min}$ and consequently stained with oil red O (5 g/L in $60 \%$ isopropanol; Merck).

\section{Chondrogenic differentiation}

To assess the chondrogenic potential of each specimen, $2.5 \times 10^{5} \mathrm{hBMSC}$ from each donor were pelleted by centrifugation at $200 \times g$ for $5 \mathrm{~min}$. Pellets were incubated in $0.5 \mathrm{~mL}$ control medium containing DMEM FG0435 (Biochrom) supplemented with $20 \mathrm{mmol} / \mathrm{L}$ HEPES-buffer (Biochrom), $1 \%$ penicillin/ streptomycin $(100 \mathrm{U} / \mathrm{mL} / 100 \mu \mathrm{g} / \mathrm{mL}$; Biochrom), $0.1 \mu \mathrm{mol} / \mathrm{L}$ dexamethasone (Merck), $10 \mu \mathrm{L} / \mathrm{mL}$ ITS (Sigma-Aldrich), $170 \mu \mathrm{mol} / \mathrm{L}$ ascorbate-2-phosphate (Sigma-Aldrich), $1 \mathrm{mmol} / \mathrm{L} \mathrm{Na}$-pyruvate (Biochrom) and $350 \mu \mathrm{mol} / \mathrm{L}$ proline (Carl Roth). After $1 \mathrm{~d}$, control medium was replaced by induction medium, with $10 \mathrm{ng} / \mathrm{mL}$ TGF- $\beta 3$ added to the control medium, for chondrogenic differentiation. Each medium was changed on a weekly basis. Histological specimens were harvested at day 28 . They were fixed in $4 \%$ formalin solution for $30 \mathrm{~min}$ and embedded in Tissue$\mathrm{Tek}^{\circledR}$ O.C.T. (Sakura Finetek, Tokyo, Japan) while using liquid nitrogen. $5 \mu \mathrm{m}$-thick frozen sections were stained using $0.1 \%$ safranin $\mathrm{O}$ and covered using Vitro Clud ${ }^{\circledR}$ (Langenbrinck, Freiburg, Germany). At $40 \times$ magnification, the quality of chondrogenic differentiation was assessed and the area covered by the pellet in relation to the total area was evaluated to assess the pellet growth.

\section{Digital processing and statistics}

All samples were assessed by light microscopy. Images were evaluated by automatic thresholdbased segmentation with an in-house-coded, Javabased software. Results were collected in Excel for Mac 14.7.7 (Microsoft) and processed using Wizard Statistics 1.9.16 (Evan Miller, Chicago, IL, USA). Normal distribution of the data was evaluated by Kolmogorov-Smirnov test. Non-normally distributed groups were compared by their median using MannWhitney U test. A $p \leq 0.05$ was considered to be

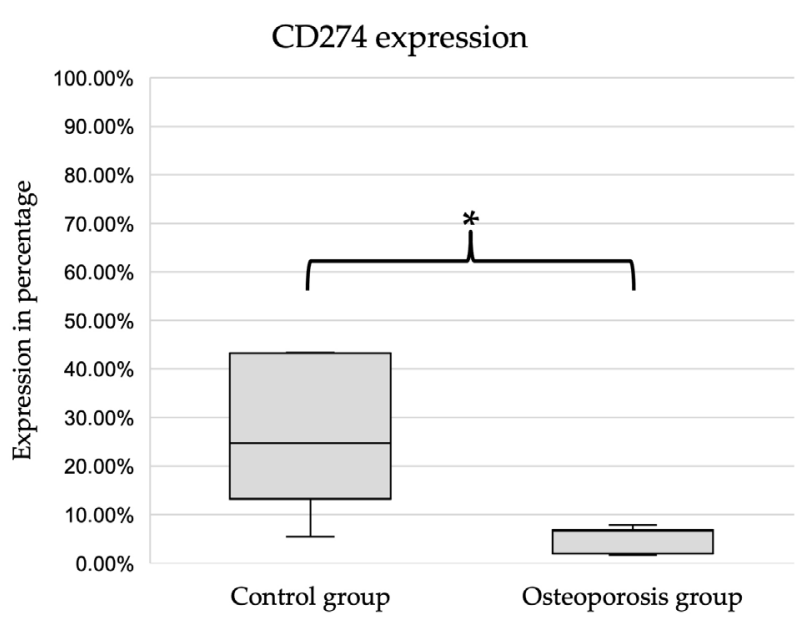

Fig. 1. Expression of CD274 was significantly lower in hBMSCs of the osteoporosis group than in control group $\left.{ }^{*} p=0.007\right)$.

statistically significant. Further statistical analyses were carried out using SPSS Statistics 24 (IBM).

\section{Results}

Cells from seven donors suffering from symptomatic osteoporosis were compared to seven samples from healthy patients (control group). Groups were matched by age and gender. Donors suffering from cancer and autoimmune disorders were excluded from the study. Immunotherapy, chemotherapy and regular intake of steroidal drugs were further criteria for exclusion. Previous intake of anti-resorptive substances was not taken into account. By gender, distribution within the groups was equivalent to 5 female : 2 male donors. Average ages were 80.00 years ( \pm 7.24 years) and 80.14 years ( \pm 3.52 years), for the osteoporosis and control group, respectively. 


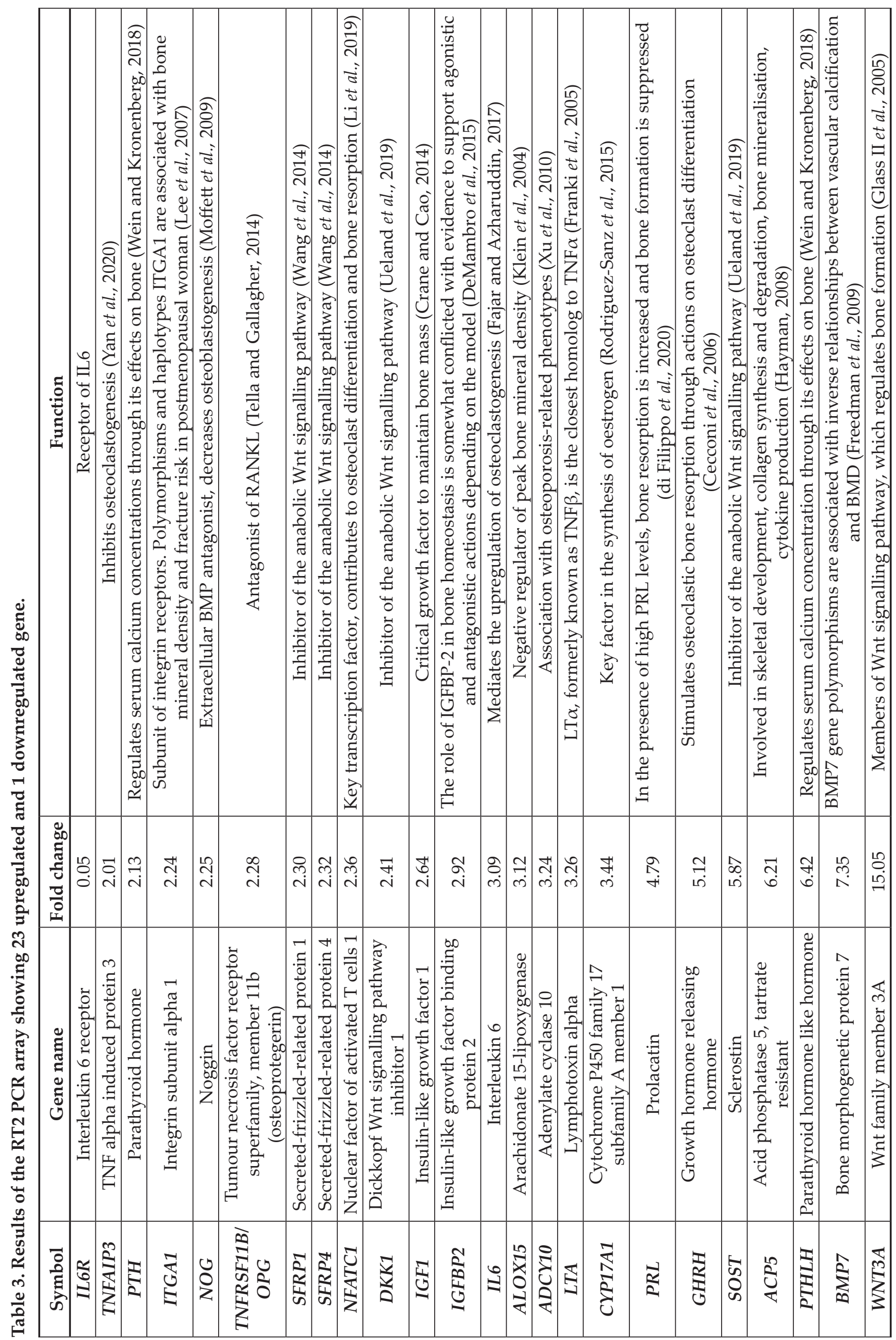




\section{CFU-F assay}

CFU assays were carried out for both groups at P1. Cells from osteoporotic donors formed $3.74( \pm 3.13)$ colonies per 100 cells seeded, cells from the control group $4.40( \pm 4.86)$. The result was not statistically significant $(p=1.000)$.

\section{Expression of MSC-specific surface antigens}

Surface antigen expression of CD11b, CD11c, CD15, CD19, CD29, CD31, CD34, CD44, CD45, CD73, CD90, CD105, CD166 and CD274 was measured at P3 by FC (Table 2). Cells displayed a typical pattern of MSC-specific surface antigens. No significant differences were observed between the surface antigens in the osteoporosis and control group, except for CD274 (PD-L1). MSCs from osteoporotic donors had significantly less CD274 surface expression $(4.98 \% \pm 2.38 \%)$ than those from the control group (26.03 \% $\pm 13.39 \%$; Fig. 1). Differences between both groups were statistically significant $(p=0.007)$.

\section{Gene regulation (RT2 PCR osteoporosis array)}

Abbreviation, gene name and gene function of the upregulated and downregulated genes of the RT2 Profiler PCR Array Osteoporosis are listed in Table 3 . The analysis resulted in 23 upregulated and one downregulated gene in the RNA of hBMSCs from osteoporotic patients compared to healthy ones. The most expressed gene was WNT3A (fold change: 15.05). Interestingly, also many inhibitors of the anabolic Wnt signalling pathway as DKK1 (fold change: 2.41), SFRP1 (fold change: 2.30) and SFRP4 (fold change: 2.32) as well as SOST (fold change:

a
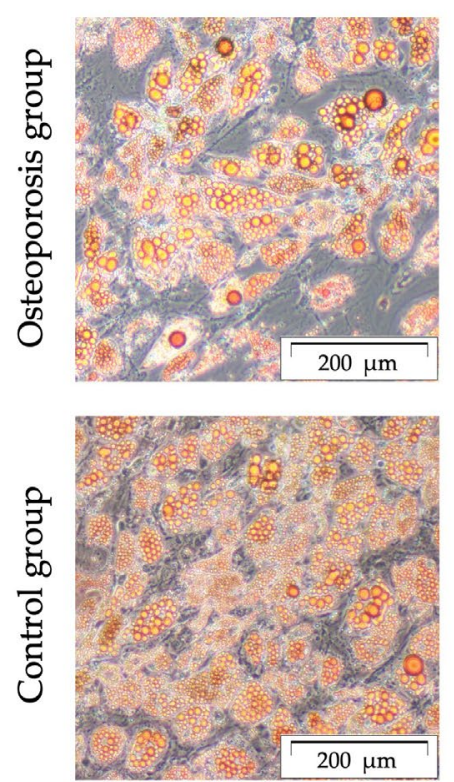

$\mathrm{b}$
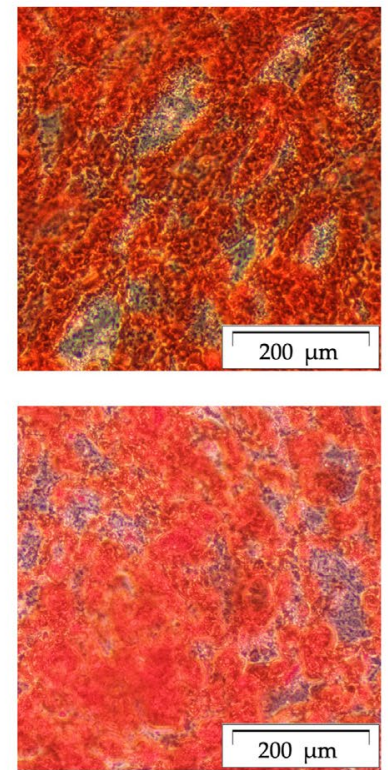

5.12) were significantly upregulated in samples from osteoporotic patients compared to healthy controls. Furthermore, markers known to stimulate bone resorption as ALOX15 (fold change: 3.12), GHRH (fold change: 5.12), IL6 (fold change: 3.09), NFATC1 (fold change: 2.36), PRL (fold change: 4.79), PTH (fold change: 2.13 ) and PTHLH (fold change: 6.42 ) were significantly increased in osteoporotic patients. The only downregulated gene was IL6R, with a fold change of 0.05 .

\section{Gene expression}

mRNA expression of CD274, CD279 and CD152 was examined for five randomly chosen specimens per group. While CD279 was not expressed in hBMSCs, the mRNA expression of CD152 showed no significant difference $(p>0.05)$ in cells from osteoporotic patients (fold change: $0.833 \pm 0.623$ ) compared to controls (fold change: $1.053 \pm 0.651)$. In contrast, CD274 mRNA expression was significantly $(p=0.016)$ lower in hBMSCs from osteoporotic patients (fold change: $0.648 \pm 0.209$ ) compared to controls (fold change: $1.443 \pm 0.745)$.

\section{Adipogenesis}

Adipogenic differentiation was induced by treatment with insulin and dexamethasone. All specimens were capable of adipogenic differentiation. At day 28, within the osteoporosis group, $35.02 \%( \pm 22.71 \%)$ of the investigated area was covered with lipid droplets (Fig. 2a), while $38.10 \%( \pm 11.31 \%$ ) of the area had undergone adipogenic differentiation within the control group. Differences were not

c
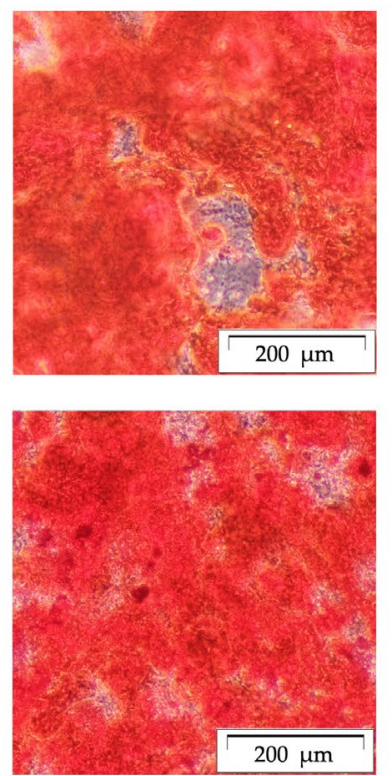

d
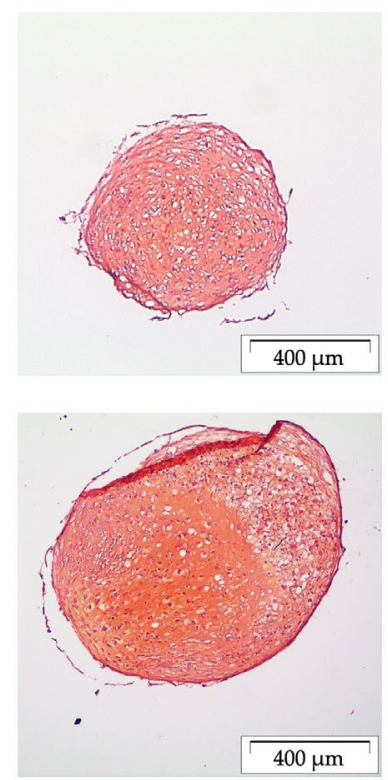

Fig. 2. Representative images displaying the multipotent differentiation potential of hBMSCs from one donor of the osteoporosis group and one donor of the control group. All images display samples after incubation with the respective induction medium. (a) Adipogenic differentiation at day 28, stained with oil red $O$. Images taken at 100× magnification. (b) Osteogenic differentiation at day 28: stained with alizarin red. Images taken at 100× magnification. (c) Osteogenic differentiation at day 42: stained with alizarin red. Images taken at 100× magnification. (d) Chondrogenic differentiation at day 28: stained with safranin O. Images taken at $40 \times$ magnification. Scale bars as indicated on the image. 
statistically significant $(p>0.05)$. The non-induced samples showed no signs of major spontaneous cell differentiation.

\section{Osteogenesis}

As observable signs of osteogenic differentiation become visible later than signs of adipogenic differentiation, measurements were carried out at day 28 and 42. The non-induced samples showed no signs of major spontaneous cell differentiation. At day 28, the area covered by stained calcium deposits was $85.39 \%( \pm 10.74 \%)$ in the osteoporosis group and $83.40 \%( \pm 15.40 \%)$ in the control group (Fig. 2 b). By day $42,84.09 \%( \pm 5.71 \%)$ of the area in the osteoporosis group and $94.09 \%( \pm 5.71 \%)$ of the area in the control group (Fig. 2c) were covered by histological signs of osteogenic differentiation. Differences between groups were not statistically significant $(p>0.05)$.

\section{Chondrogenesis}

Chondrogenic differentiation was induced by treatment with TGF- $\beta 3$. All induced samples in the osteoporosis or control group were capable of chondrogenic differentiation. The non-induced samples showed no signs of major spontaneous cell differentiation. By day 28, the relative area covered was $17.28 \%( \pm 8.56 \%)$ within the osteoporosis group versus $27.04 \%$ ( $\pm 15.76 \%$ ) in control group (Fig. $2 \mathrm{~d}$ ). Differences were not statistically significant $(p>0.05)$.

\section{Discussion}

Osteoporosis is a disease of increasing economic importance (Kling et al., 2014). Even though a variety of screening methods are available, osteoporosis is still considered to be under-diagnosed and undertreated (Golob and Laya, 2015). A variety of therapy approaches exists, some with severe side-effects (Kling et al., 2014). Drugs with direct long-term effect on bone metabolism such as bisphosphonates and monoclonal antibodies (i.e. Denosumab) are frequently administered. Nevertheless, they come with severe long-term side effects, e.g. MRONJ (Fliefel et al., 2015; Kling et al., 2014; Lemound et al., 2017; Pichardo et al., 2013; Ruggiero et al., 2014). Cell-based therapies might pose an alternative to current standard therapy (Antebi et al., 2014; Kassem et al., 2004; Mikami et al., 2014). As they may be able to provide a causal therapy approach, they could be especially useful for young patients to avoid long-term drug administration. To develop these specific therapy approaches for osteoporosis, complete and profound understanding of underlying pathomechanisms is essential. Therefore, the aim of the present study was to identify differences in the stem cell characteristics of osteoporosis patients compared to healthy subjects.

Some studies in the field of bone metabolism (Rodríguez et al., 1999) propose decreased osteogenic differentiation potential for BMSCs from osteoporotic patients. This is in disagreement with more recent, methodically more robust studies (Haddouti et al., 2020) describing that MSCs from osteoporotic and healthy patients possess similar differentiation properties. In the present study, osteogenesis did not seem to be impaired on a cellular level in vitro. In line with this observation, Prall et al. (2013) have suggested that MSCs from osteoporotic donors might have impaired signal transduction but sustained osteoinduction upon stimulation. Therefore, an osteoporosis array was performed to examine differences between osteoporotic and healthy patients on the gene expression level. Results showed, on the one hand, a significant increase in genes associated with osteoclast activation and, on the other hand, an inhibition of the anabolic Wnt signalling pathway. These results were in line with the findings of other working groups who showed that inhibitors of the Wnt signalling, such as DKK1 or SOST, play an important role in the development of osteoporosis (Baron and Gori, 2018; Baron and Kneissel, 2013). In addition, in osteoporotic patients, the balance between bone formation by osteoblasts and bone degradation by osteoclasts is shifted in favour of osteoclasts, wherefore many therapeutic strategies have been developed that aim at inhibiting excessive bone resorption (Rachner et al., 2011). Furthermore, clinical findings in MRI studies, proposing a connection between increased amounts of bone marrow fat and decreased bone density (Paccou et al., 2015), suggest possible differences in adipogenic and osteogenic differentiation potential. At a molecular level, different concentrations of pro-adipogenic and pro-inflammatory regulatory factors are reported for osteoporotic bone marrow (Pino et al., 2012). In the present study, no significant differences in adipogenic, osteogenic and chondrogenic differentiation potential of hBMSCs could be found in vitro, substantiating the assumption of a strong modulatory effect of the surrounding environment within the bone marrow in vivo.

The surface antigen expression on MSCs is still a subject of current research and several amendments have been made to the criteria postulated by Dominici et al. (2006). The meaning of the expression of some antigens such as HLA-DR (Bocelli-Tyndall et al., 2010; Dominici et al., 2006; Larghero et al., 2008; Tarte et al., 2010) and CD34 (Dominici et al., 2006; Lin et al., 2012) remains unclear. Regarding HLA-DR expression, it was shown that an exposure of hBMSCs to FGF2 is suspected to lead to its expression in vitro (Bocelli-Tyndall et al., 2015). As cells in the present study were exposed to FGF2 prior to FC analysis, HLA-DR expression was, as postulated by Tarte $e t$ al. (2010), excluded from the minimal criteria for MSCs (Dominici et al., 2006). Regarding CD34, it is highly controversial whether its non-expression should be considered as a minimal criterion, as postulated by Dominici et al. (2006). In the present study, more than $5 \%$ of the cells expressed CD34. As cells were 
propagated in culture, CD34 non-expression was not considered as an appropriate minimal criterion for MSCs, in agreement with Lin et al. (2012). The other surface antigens that should be measured according to the ISCT criteria were, as expected, positive (CD105, CD73 and CD90) or negative (CD45, CD11b, CD19) in both patients' groups without significant differences. In addition to the criteria defined by Dominici et al. (2006), further surface antigens were tested by FC: CD29, CD44, CD166, CD11c, CD15 and CD31, as postulated in the literature (Bara et al., 2014; Dominici et al., 2006; Machado et al., 2013). These criteria were sufficiently met by the cells, thus supporting they represented sufficiently pure MSC populations.

Besides degenerative factors, $\mathrm{B}$ and $\mathrm{T}$ cells influence osteoclasts via RANKL pathway and other immunological pathologies involving CD279 deficiency and CD40 expression have been described (Arron and Choi, 2000; Li et al., 2007; Nagahama et al., 2004; Pietschmann et al., 2016). CD274 expression rates have been described as highly heterogenic among different hBMSC samples and to correlate negatively with donors' age (Siegel et al., 2013). To the authors' knowledge, gender differences have so far not been reported. Nagahama et al. (2004) described a link between deficiency of CD279 and bone malformation without effect on the rate of osteogenesis in vitro. They showed the occurrence of an osteoporotic phenotype for CD279 deficient mice, suggesting an underlying mechanism mainly based on the modulation of the activation of osteoclastprogenitors.

As CD274 (PD-L1) is the ligand of CD279, all samples in the study were assessed for their CD274 expression by FC and real-time PCR. An increase in CD274 concentration was expected in osteoporotic patients, as a deficiency in the receptor CD279 leads to osteopetrosis. However, in contrast to expectations, a 5-fold reduction in CD274 concentration at protein and a $50 \%$ decrease at gene level were found in osteoporotic patients. Additionally, Cheishvili et al. (2018) found the hypermethylation of PDCD1, the gene locus of CD279, to be associated with the occurrence of osteoporosis. As the results of the present study showed an association between CD274 deficiency and osteoporosis, they can be considered consistent with those of Cheishvili et al. (2018). Furthermore, IL6R blockade prevents the upregulation of CD274 (Eriksson et al., 2019) and IL6 signal pathway is necessary for CD274 stability (Chan et al., 2019), as well as the maximum expression of CD274 is only possible in the presence of IL6 (Jin et al., 2013). As significantly downregulated IL6R values and increased IL6 concentrations were detected in the osteoporosis gene array, CD274 could be an interesting candidate in the field of bone and osteoporosis research. The underlying mechanisms and the signalling pathways involved in this setting are still unknown and are the subject of further research.

\section{Limitations}

Some common drugs used in prophylactic treatment of patients at risk of or suffering from osteoporosis, such as bisphosphonates, have a long half-life (Lemound et al., 2017; Pichardo et al., 2013). Prior administrations, even decades, may therefore lead to effects of these substances onto the patient's bone metabolism. As this is frequently not remembered by the patient, prior intake of anti-resorptive substances was not considered for the present study.

It cannot be completely excluded that some drugs or interventions might influence CD274 regulation. Even though it is mainly known for chemotherapeutics, whose administration was a criterion for exclusion, a bias regarding this point cannot be completely ruled out.

The results presented were based on in vitroexpanded hBMSCs. This was necessary due to the regulations of the institutional review board, as cells were obtained from a biobank containing samples from human donors undergoing standard surgical procedures. Yet, in vitro expansion may diminish the quality of cells, especially in aged individuals. Thus, further experiments should be conducted to verify the findings of the study in vivo.

\section{Conclusions}

CD274 expression on hBMSCs in vitro was found to be significantly reduced in patients suffering from osteoporosis. Interactions between CD274 (PD-L1), its receptor CD279 on T cells and bone metabolism have been described (Nagahama et al., 2004). The presented findings supported the theory of strong immunological components in the pathogenesis of osteoporosis (Arron and Choi, 2000). They may be a central starting point for further investigations regarding the pathogenesis of osteoporosis and into cell-based therapies involving MSCs.

\section{Acknowledgements}

We would like to thank the donors and surgeons of the Trauma Department at Hannover Medical School for providing us with bone marrow samples and Claudia Pütz, Melanie Weiß and Johanna Ehlers for their valuable assistance. The Institute of Functional and Applied Anatomy at Hannover Medical School generously made it possible for us to use their flow cytometer for this study.

We acknowledge support by the German Research Foundation (DFG) and the Open Access Publication Fund of Hannover Medical School (MHH).

The underlying study was financed solely by Hannover Medical School and Else Kröner-FreseniusStiftung [Grant No. 2016-A188].

The authors declare to have no potential conflicts of interest. 
The data used to support the findings of this study are available upon request to the the corresponding author upon request.

\section{References}

Aghebati-Maleki L, Dolati S, Zandi R, Fotouhi A, Ahmadi M, Aghebati A, Nouri M, Kazem Shakouri S, Yousefi M (2019) Prospect of mesenchymal stem cells in therapy of osteoporosis: A review. J Cell Physiol 234: 8570-8578.

Antebi B, Pelled G, Gazit D (2014) Stem cell therapy for osteoporosis. Curr Osteoporos Rep 12: 41-47.

Arron JR, Choi Y (2000) Bone versus immune system. Nature 408: 535-536.

Banas A, Teratani T, Yamamoto Y, Tokuhara M, Takeshita F, Quinn G, Okochi H, Ochiya T (2007) Adipose tissue-derived mesenchymal stem cells as a source of human hepatocytes. Hepatology 46: 219228.

Bara JJ, Richards RG, Alini M, Stoddart MJ (2014) Concise review: bone marrow-derived mesenchymal stem cells change phenotype following in vitro culture: implications for basic research and the clinic. Stem Cells 32: 1713-1723.

Baron R, Gori F (2018) Targeting WNT signaling in the treatment of osteoporosis. Curr Opin Pharmacol 40: 134-141.

Baron R, Kneissel M (2013) WNT signaling in bone homeostasis and disease: from human mutations to treatments. Nat Med 19: 179-192.

Bocelli-Tyndall C, Trella E, Frachet A, Zajac P, Pfaff D, Geurts J, Heiler S, Barbero A, Mumme M, Resink TJ, Schaeren S, Spagnoli GC, Tyndall A (2015) FGF2 induces RANKL gene expression as well as IL1 $\beta$ regulated MHC class II in human bone marrowderived mesenchymal progenitor stromal cells. Ann Rheum Dis 74: 260-266.

Bocelli-Tyndall C, Zajac P, Di Maggio N, Trella E, Benvenuto F, Iezzi G, Scherberich A, Barbero A, Schaeren S, Pistoia V, Spagnoli G, Vukcevic M, Martin I, Tyndall A (2010) Fibroblast growth factor 2 and platelet-derived growth factor, but not platelet lysate, induce proliferation-dependent, functional class II major histocompatibility complex antigen in human mesenchymal stem cells. Arthritis Care Res 62: 3815-3825.

Bundkirchen K, MacKe C, Angrisani N, Schäck LM, Noack S, Fehr M, Krettek C, Neunaber C (2018) Hemorrhagic shock alters fracture callus composition and activates the IL6 and RANKL/OPG pathway in mice. J Trauma Acute Care Surg 85: 359-366.

Burge R, Dawson-Hughes B, Solomon DH, Wong JB, King A, Tosteson A (2007) Incidence and economic burden of osteoporosis-related fractures in the United States, 2005-2025. J Bone Miner Res 22: 465-475.

Čamernik K, Mihelič A, Mihalič R, Haring G, Herman S, Marolt Presen D, Janež A, Trebše R, Marc J, Zupan J (2020) Comprehensive analysis of skeletal muscle- and bone-derived mesenchymal stem/stromal cells in patients with osteoarthritis and femoral neck fracture. Stem Cell Res Ther 11: 146. DOI: 10.1186/s13287-020-01657-z.

Cecconi E, Gasperi M, Genovesi M, Bogazzi F, Grasso L, Cetani F, Procopio M, Marcocci C, Bartalena L, Martino E (2006) The reduction of bone mineral density in postmenopausal women with primary hyperparathyroidism is higher in the presence of concomitant GH secretion impairment. Eur J Endocrinol 155: 41-45.

Chamberlain G, Fox J, Ashton B, Middleton J (2007) Concise review: mesenchymal stem cells: their phenotype, differentiation capacity, immunological features, and potential for homing. Stem Cells 25: 2739-2749.

Chan LC, Li CW, Xia W, Hsu JM, Lee HH, Cha JH, Wang HL, Yang WH, Yen EY, Chang WC, Zha Z, Lim SO, Lai YJ, Liu C, Liu J, Dong Q, Yang Y, Sun L, Wei Y, Nie L, Hsu JL, Li H, Ye Q, Hassan MM, Amin HM, Kaseb AO, Lin X, Wang SC, Hung MC (2019) IL-6/ JAK1 pathway drives PD-L1 Y112 phosphorylation to promote cancer immune evasion. J Clin Invest 129: 3324-3338.

Cheishvili D, Parashar S, Mahmood N, Arakelian A, Kremer R, Goltzman D, Szyf M, Rabbani SA (2018) Identification of an epigenetic signature of osteoporosis in blood DNA of postmenopausal women. J Bone Miner Res 33: 1980-1989.

Crane JL, Cao X (2014) Function of matrix IGF-1 in coupling bone resorption and formation. J Mol Med 92: 107-115.

Cummings SR, Melton LJ (2002) Osteoporosis I: Epidemiology and outcomes of osteoporotic fractures. Lancet 359: 1761-1767.

de Vasconcellos Machado C, da Silva Telles PD, Nascimento ILO (2013) Immunological characteristics of mesenchymal stem cells. Rev Bras Hematol Hemoter 35: 62-67.

DeMambro VE, Le PT, Guntur AR, Maridas DE, Canalis E, Nagano K, Baron R, Clemmons DR, Rosen CJ (2015) Igfbp2 deletion in ovariectomized mice enhances energy expenditure but accelerates bone loss. Endocrinology 156: 4129-4140.

Docheva D, Popov C, Mutschler W, Schieker M (2007) Human mesenchymal stem cells in contact with their environment: Surface characteristics and the integrin system. J Cell Mol Med 11: 21-38.

Dominici M, Le Blanc K, Mueller I, SlaperCortenbach I, Marini F, Krause DS, Deans RJ, Keating A, Prockop DJ, Horwitz EM (2006) Minimal criteria for defining multipotent mesenchymal stromal cells. The International Society for Cellular Therapy position statement. Cytotherapy 8: 315-317.

Duque G, Rivas D (2007) Alendronate has an anabolic effect on bone through the differentiation of mesenchymal stem cells. J Bone Miner Res 22: 16031611.

Eriksson E, Milenova I, Wenthe J, Moreno R, Alemany R, Loskog A (2019) IL-6 signaling blockade during CD40-mediated immune activation favors 
antitumor factors by reducing TGF- $\beta$, collagen type I, and PD-L1/PD-1. J Immunol 202: 787-798.

Fajar JK, Azharuddin A (2017) The association between interleukin 6-174 G/C gene polymorphism and the risk of osteoporosis: a meta-analysis. J Taibah Univ Med Sci 12: 212-220.

di Filippo L, Doga M, Resmini E, Giustina A (2020) Hyperprolactinemia and bone. Pituitary 23: 314-321.

Fliefel R, Tröltzsch M, Kühnisch J, Ehrenfeld M, Otto S (2015) Treatment strategies and outcomes of bisphosphonate-related osteonecrosis of the jaw (BRONJ) with characterization of patients: a systematic review. Int J Oral Maxillofac Surg 44: 568585.

Franki AS, Beneden K Van, Dewint P, Meeus I, Veys E, Deforce D, Elewaut D (2005) Lymphotoxin $\alpha 1 \beta 2$ : a critical mediator in V $\alpha 14$ i NKT cell differentiation. Mol Immunol 42: 413-417.

Freedman BI, Bowden DW, Ziegler JT, Langefeld $\mathrm{CD}$, Lehtinen $\mathrm{AB}$, Rudock ME, Lenchik L, Hruska KA, Register TC, Carr JJ (2009) Bone morphogenetic protein 7 (BMP7) gene polymorphisms are associated with inverse relationships between vascular calcification and BMD: the diabetes heart study. J Bone Miner Res 24: 1719-1727.

Gibon E, Lu LY, Nathan K, Goodman SB (2017) Inflammation, ageing, and bone regeneration. J Orthop Transl 10: 28-35.

Glass DA, Bialek P, Ahn JD, Starbuck M, Patel MS, Clevers H, Taketo MM, Long F, McMahon AP, Lang RA, Karsenty G (2005) Canonical Wnt signaling in differentiated osteoblasts controls osteoclast differentiation. Dev Cell 8: 751-764.

Golob AL, Laya MB (2015) Osteoporosis: Screening, prevention, and management. Med Clin North Am 99: 587-606.

Haasters F, Docheva D, Gassner C, Popov C, Böcker W, Mutschler W, Schieker M, Prall WC (2014) Mesenchymal stem cells from osteoporotic patients reveal reduced migration and invasion upon stimulation with BMP-2 or BMP-7. Biochem Biophys Res Commun 452: 118-123.

Haddouti EM, Randau TM, Hilgers C, Masson W, Pflugmacher R, Burger C, Gravius S, Schildberg FA (2020) Vertebral bone marrow-derived mesenchymal stromal cells from osteoporotic and healthy patients possess similar differentiation properties in vitro. Int J Mol Sci 21: 8309. DOI: 10.3390/ijms21218309.

Hayman A (2008) Tartrate-resistant acid phosphatase (TRAP) and the osteoclast/immune cell dichotomy. Autoimmunity 41: 218-223.

Jin Y-H, Hou W, Kang HS, Koh C-S, Kim BS (2013) The role of interleukin-6 in the expression of PD-1 and PDL-1 on central nervous system cells following infection with theiler's murine encephalomyelitis virus. J Virol 87: 11538-11551.

Johnell O, Kanis J (2005) Epidemiology of osteoporotic fractures. Osteoporos Int 16: S3-7.

Kassem M, Kristiansen M, Abdallah BM (2004) Mesenchymal stem cells: Cell biology and potential use in therapy. Basic Clin Pharmacol Toxicol 95: 209214.

Kassem M, Marie PJ (2011) Senescence-associated intrinsic mechanisms of osteoblast dysfunctions. Aging Cell 10: 191-197.

Klein RF, Allard J, Avnur Z, Nikolcheva T, Rotstein D, Carlos AS, Shea M, Waters RV, Belknap JK, Peltz G, Orwoll ES (2004) Regulation of bone mass in mice by the lipoxygenase gene Alox15. Science 303: 229-232.

Kling JM, Clarke BL, Sandhu NP (2014) Osteoporosis prevention, screening, and treatment: a review. J Womens Health (Larchmt) 23: 563-572.

Kretlow JD, Jin YQ, Liu W, Zhang WJ, Hong TH, Zhou G, Baggett LS, Mikos AG, Cao Y (2008) Donor age and cell passage affects differentiation potential of murine bone marrow-derived stem cells. BMC Cell Biol 9: 60. DOI: 10.1186/1471-2121-9-60.

Larghero J, Farge D, Braccini A, Lecourt S, Scherberich A, Foïs E, Verrecchia F, Daikeler T, Gluckman E, Tyndall A, Bocelli-Tyndall C (2008) Phenotypical and functional characteristics of in vitro expanded bone marrow mesenchymal stem cells from patients with systemic sclerosis. Ann Rheum Dis 67: 443-449.

Lee HJ, Kim SY, Koh JM, Bok J, Kim KJ, Kim KS, Park MH, Shin HD, Park BL, Kim TH, Hong JM, Park EK, Kim DJ, Oh B, Kimm K, Kim GS, Lee JY (2007) Polymorphisms and haplotypes of integrin $\alpha 1$ (ITGA1) are associated with bone mineral density and fracture risk in postmenopausal Koreans. Bone 41: 979-986.

Lemound J, Muecke T, Zeller AN, Lichtenstein J, Eckardt A, Gellrich NC (2018) Nasolabial flap improves healing in medication-related osteonecrosis of the jaw. J Oral Maxillofac Surg 76: 877-885.

Li X, Yang L, Guo Z (2019) miR-193-3p ameliorates bone resorption in ovariectomized mice by blocking NFATc1 signaling. Int J Clin Exp Pathol 12: 4077-4086.

Li Y, Toraldo G, Li A, Yang X, Zhang H, Qian WP, Weitzmann MN (2007) B cells and T cells are critical for the preservation of bone homeostasis and attainment of peak bone mass in vivo. Blood 109: 38393848.

Lin CS, Ning H, Lin G, Lue TF (2012) Is CD34 truly a negative marker for mesenchymal stromal cells? Cytotherapy 14: 1159-1163.

Mikami Y, Matsumoto T, Kano K, Toriumi T, Somei M, Honda MJ, Komiyama K (2014) Current status of drug therapies for osteoporosis and the search for stem cells adapted for bone regenerative medicine. Anat Sci Int 89: 1-10.

Moffett SP, Dillon KA, Yerges LM, Goodrich LJ, Nestlerode C, Bunker CH, Wheeler VW, Patrick AL, Zmuda JM (2009) Identification and association analysis of single nucleotide polymorphisms in the human noggin (NOG) gene and osteoporosis phenotypes. Bone 44: 999-1002.

Nagahama K, Aoki K, Nonaka K, Saito H, Takahashi M, Varghese BJ, Shimokawa H, Azuma M, Ohya K, Ohyama K (2004) The deficiency of 
immunoregulatory receptor PD-1 causes mild osteopetrosis. Bone 35: 1059-1068.

Nicoletti G, Passaro I, Malovini A, Faga A, Toffola ED (2013) Objective integrated assessment of functional outcomes in reduction mammaplasty. Plast Reconstr Surg Glob Open 1: 32-39.

Ogata K, Katagiri W, Osugi M, Kawai T, Sugimura Y, Hibi H, Nakamura S, Ueda M (2015) Evaluation of the therapeutic effects of conditioned media from mesenchymal stem cells in a rat bisphosphonaterelated osteonecrosis of the jaw-like model. Bone 74: 95-105.

Paccou J, Hardouin P, Cotten A, Penel G, Cortet B (2015) The role of bone marrow fat in skeletal health: Usefulness and perspectives for clinicians. J Clin Endocrinol Metab 100: 3613-3621.

Pichardo SEC, Kuypers SCC, Van Merkesteyn JPR (2013) Denosumab osteonecrosis of the mandible: a new entity? A case report. J Craniomaxillofacial Surg 41: e65-e69.

Pietschmann P, Mechtcheriakova D, Meshcheryakova A, Föger-Samwald U, Ellinger I (2016) Immunology of osteoporosis: a mini-review. Gerontology 62: 128-137.

Pino AM, Rosen CJ, Pablo Rodríguez J (2012) In osteoporosis, differentiation of mesenchymal stem cells (MSCs) improves bone marrow adipogenesis. Biol Res 45: 279-287.

Prall WC, Haasters F, Heggebö J, Polzer H, Schwarz C, Gassner C, Grote S, Anz D, Jäger M, Mutschler W, Schieker M (2013) Mesenchymal stem cells from osteoporotic patients feature impaired signal transduction but sustained osteoinduction in response to BMP-2 stimulation. Biochem Biophys Res Commun 440: 617-622.

Rachner TD, Khosla S, Hofbauer LC (2011) Osteoporosis: now and the future. Lancet 377: 12761287.

Rodríguez-Sanz M, García-Giralt N, PrietoAlhambra D, Servitja S, Balcells S, Pecorelli R, Díez-Pérez A, Grinberg D, Tusquets I, Nogues X (2015) CYP11A1 expression in bone is associated with aromatase inhibitor-related bone loss. J Mol Endocrino. 55: 69-79.

Rodríguez JP, Garat S, Gajardo H, Pino AM, Seitz G (1999) Abnormal osteogenesis in osteoporotic patients is reflected by altered mesenchymal stem cells dynamics. J Cell Biochem 75: 414-423.

Rosen CJ, Bouxsein ML (2006) Mechanisms of disease: Is osteoporosis the obesity of bone? Nat Clin Pract Rheumatol 2: 35-43.

Ruggiero SL, Dodson TB, Fantasia J, Goodday R, Aghaloo T, Mehrotra B, O'Ryan F (2014) American association of oral and maxillofacial surgeons position paper on medication-related osteonecrosis of the jaw - 2014 update. J Oral Maxillofac Surg 72: 1938-1956.

Schäck LM, Noack S, Weist R, Jagodzinski M, Krettek C, Buettner M, Hoffmann A (2013) Analysis of surface protein expression in human bone marrow stromal cells: new aspects of culture-induced changes, inter-donor differences and intracellular expression. Stem Cells Dev 22: 3226-3235.

Siegel G, Kluba T, Hermanutz-Klein U, Bieback K, Northoff H, Schäfer R (2013) Phenotype, donor age and gender affect function of human bone marrowderived mesenchymal stromal cells. BMC Med 11: 146. DOI: 10.1186/1741-7015-11-146.

Tarte K, Gaillard J, Lataillade JJ, Fouillard L, Becker M, Mossafa H, Tchirkov A, Rouard H, Henry C, Splingard M, Dulong J, Monnier D, Gourmelon P, Gorin NC, Sensebé L (2010) Clinical-grade production of human mesenchymal stromal cells: occurrence of aneuploidy without transformation. Blood 115: 15491553.

Tella SH, Gallagher JC (2014) Prevention and treatment of postmenopausal osteoporosis. J Steroid Biochem Mol Biol 142: 155-170.

Ueland T, Stilgren L, Bollerslev J (2019) Bone matrix levels of dickkopf and sclerostin are positively correlated with bone mass and strength in postmenopausal osteoporosis. Int J Mol Sci 20: 2896. DOI: 10.3390/ijms20122896.

Wang S, Qu X, Zhao RC (2012) Clinical applications of mesenchymal stem cells. J Hematol Oncol 5: 19. DOI: 10.1186/1756-8722-5-19.

Wang Y, Li YP, Paulson C, Shao JZ, Zhang X, Wu M, Chen W (2014) Wnt and the Wnt signaling pathway in bone development and disease. Front Biosci (Landmark Ed) 19: 379-407.

Wein MN, Kronenberg HM (2018) Regulation of bone remodeling by parathyroid hormone. Cold Spring Harb Perspect Med 8: a031237. DOI: 10.1101/ cshperspect.a031237.

Xu XH, Dong SS, Guo Y, Yang TL, Lei SF, Papasian CJ, Zhao M, Deng HW (2010) Molecular genetic studies of gene identification for osteoporosis: the 2009 update. Endocr Rev 31: 447-505.

Yan K, Wu C, Ye Y, Li L, Wang X, He W, Ren S, Xu Y (2020) A20 inhibits osteoclastogenesis via TRAF6-dependent autophagy in human periodontal ligament cells under hypoxia. Cell Prolif 53: e12778. DOI: $10.1111 /$ cpr.12778.

Zhao RC, Liao L, Han Q (2004) Mechanisms of and perspectives on the mesenchymal stem cell in immunotherapy. J Lab Clin Med 143: 284-291.

Zhou S, Greenberger JS, Epperly MW, Goff JP, Adler C, Leboff MS, Glowacki J (2008) Age-related intrinsic changes in human bone-marrow-derived mesenchymal stem cells and their differentiation to osteoblasts. Aging Cell 7: 335-343.

\section{Web Reference}

1. http://www.qiagen.com/geneglobe [20.04.21]

\section{Discussion with Reviewers}

Glen Niebur: Can the authors propose a pathway by which decreased CD274 expression might affect 
immune cells and consequently bone formation or resorption? Did the results point toward a potential pathway of increased osteoclastogenesis and bone loss in the endosteal niche? Is this consistent with the results of Nagahama et al. (2004)?

Authors: Unfortunately, it is not possible to answer these questions satisfactorily. After observing that CD274 was significantly downregulated in hBMSCs from osteoporotic patients, it was initially thought that this was in line with the findings of Nagahama et al. (2004). However, on a closer inspection, it turned out that a deficiency in CD274 and CD276 led to an osteoporotic phenotype. To clarify this factual situation, more precise molecular biological investigations are required, which are planned in future.

Reviewer: There is much talk of using MSCs to treat osteoporosis. How do you envisage this happening, given that MSCs do not engraft into bone very well and, in contrast to earlier expectations, do not allograft well. Do you think autologous cells engineered to express more CD274 might be useful? Authors: The present study showed for the first time a lower expression of CD274 in hBMSCs from osteoporotic patients and this both at the mRNA and protein level. The exact connection between this observation and the clinical picture of osteoporosis has to be analysed in more detail in further studies. However, this is a first indication on which further research should be carried out. Even though MSCs do not engraft into bone very well, stem cell therapy can still be successful, e.g. due to secreted factors that in turn activate surrounding cells and intervene in bone remodelling.

Editor's note: The Scientific Editor responsible for this paper was Chris Evans. 